\title{
Clinical case of influenza A with outer retinal maculopathy
}

Daini Ong MBBS(Hons), ${ }^{1,2,3}$ C Alex Harper FRANZCO ${ }^{1,2,3}$ and Xavier Fagan FRANZCO ${ }^{1}$

1, The Royal Victorian Eye and Ear Hospital, 32 Gisborne St, East Melbourne, Victoria 3002. Australia

2. Centre for Eye Research Australia, Level 1, 32 Gisborne St, East Melbourne, Victoria 3002. Australia

3. University of Melbourne, Ophthalmology, Department of Surgery, Victoria, Australia

Correspondence: Daini Ong, The Royal Victorian Eye and Ear Hospital, 32 Gisborne St, East Melbourne, Victoria 3002. Australia

Corresponding author

Email: drdainiong@gmail.com

Received 23 February 2017; accepted 2 March 2017

Conflict of interest: None

Funding sources: None

This is the author manuscript accepted for publication and has undergone full peer review but has not been through the copyediting, typesetting, pagination and proofreading process, which may lead to differences between this version and the Version of Record. Please cite this article as doi: $10.1111 /$ ceo.12944

This article is protected by copyright. All rights reserved. 
Influenza A, the most common subtype of seasonal influenza, is a significant cause of morbidity and mortality around the world, affecting 3 to 5 million people each year. ${ }^{1}$ Influenza commonly presents as a respiratory tract infection with fever and myalgia. Rarely, there have been reports of eye and ocular adnexal complications.

In the retina, influenza may have an array of clinical presentations from multiple evanescent white dot syndrome ${ }^{2}$ to retinal ischaemia. ${ }^{3}$ We report a case of outer retinal maculopathy with features of unilateral acute idiopathic macuolpathy (UAIM) in a patient with influenza $A$.

A 49-year-old Caucasian male presented with rapid loss of vision in the right eye over two days. He had flu symptoms with headache, fever and cough in the preceding four days. On nasopharyngeal swab testing, he was confirmed to have Influenza A virus.

He had a past history of a right traumatic eye injury and cataract extraction 39 years ago and a secondary anterior chamber lens insertion 16 years ago.

On ophthalmic examination, his visual acuity was $6 / 60$ and $6 / 6$ in the right and left eyes respectively, with 1+ cells in the anterior chamber $(\mathrm{AC})$ and minimal vitreous cells. His intraocular pressure (IOP) was $30 \mathrm{mmHg}$. His right fundus (Zeiss Visucam 200) had a large yellow plaque with pigmentation involving the central macular (Figure 1). Optical coherence tomography (OCT) imaging (Spectralis, Heidelberg Engineering, USA) showed increased broad based disruption of the outer retina, hyper-reflectivity, affecting the interdigitation zone, ellipsoid zone and outer plexiform layer extending to inner plexiform layer. Fluorescein Angiogram (Spectralis, Heidelberg Engineering, USA) showed disc hyperfluorescence but 
minimal macular leakage. He was treated with topical steroid drops QID and brinzolamide/timolol BD.

At one week review, the patient's vision in his right eye improved to 6/36. The inflammation in his AC had resolved and IOP had normalized. OCT revealed partial outer retinal reconstitution. However, at the follow up two weeks later, there was a worsening of his clinical course. He had 1+ anterior chamber inflammation, IOP of $30 \mathrm{mmHg}$ as well as new onset cystoid macular oedema (CMO). Topical corticosteroid and brinzolamide/timolol treatment was recommenced. One month later, visual acuity improved to 6/9, nevertheless our patient reported persisting scotoma with reduced colour perception within the area affected. The AC was quiet and CMO significantly improved.

Figure 1: Top row, fundus photo of both eyes. Middle left, short-wave fundus autofluorescence and middle right, infrared images. Bottom row, fluorescein angiogram (FFA) at 32 seconds and 5 minutes 12 seconds.

Figure 2: Top OCT scan and infra-red reflectance image at the initial presentation. Bottom left, restoration of OCT layers after 1 week after the onset of his symptoms. Right, development of cystoid macular oedema 2 weeks after presentation.

To date, this is the first reported case of influenza A causing outer maculopathy. We have chosen not to categorise it under a known clinical entity because of the atypical features. The case had features of unilateral acute idiopathic maculopathy (UAI M) however on multimodal imaging the diagnosis was not fully supported as there was no subretinal fluid or thickening on OCT. Furthermore, there was no fluorescein leakage from the affected retina in the late phases, however disc leakage was present. We did not send Coxsackie serology after his throat swab detected 
influenza. The case also does not fit with classic acute macular neuroretinopathy(AMN), as AMN is not associated with inflammation and resolution with pigmentary changes. Krill's disease was considered but the fundus did not display the described multiple pigmented spots surrounded by depigmented halos.

Influenza A has been shown to infect RPE in vivo and consequently lead to cell apoptosis. ${ }^{4}$ Clinically, the postulated RPE infection has been used to explain MEWDS and submacular haemorrhage associated with influenza. ${ }^{5}$ However, none of the cases in the literature with influenza associated retinopathy was similar to our case.

This case report adds to the building body of literature of the manifestation of influenza in the retina. The speculated pathophysiology is disruption to the blood retinal barrier and consequently viral replication or immunocomplex deposition in the area affected. Secondary complications, such as cystoid macular oedema due to inflammation, may occur and delay full visual recovery. Our case had persistent visual changes, however, the improvement was significant.

Influenza is a common disease but with rare retinal manifestations. The visual prognosis is uncertain but the initial improvement and visual recovery in our patient, despite cystoid oedema, is encouraging.

\section{REFERENCES}

1. World Health Organsiation. Influenza (Seasonal) fact sheet 2016. Accessed Feb 2017. Available from

http://www.who.int/mediacentre/factsheets/fs211/en/ 
2. Goyal S, Nazarian SM, Thayi DR, Hammond F, Petrovic V. Multiple evanescent white dot syndrome following recent influenza vaccination. Can J Ophthalmol 2013; 48: el15-6.

3. Breker DA, Stacey AW, Srinivasan A, Bursztyn LL, Trobe JD, J ohnson MW. Vision Loss Caused by Retinal and Lateral Geniculate Nucleus I nfarction in H1N1 Influenza. J Neuroophthalmol 2015; 35: 265-9.

4. Michaelis M, Geiler J, Klassert D, Doerr HW, Cinatl J, J r. Infection of human - retinal pigment epithelial cells with influenza A viruses. Invest Ophthalmol Vis Sci 2009; 50: 5419-25.

5. Weinberg RJ, Nerney JJ. Bilateral submacular hemorrhages associated with an influenza syndrome. Ann Ophthalmol 1983; 15: 710-12. 


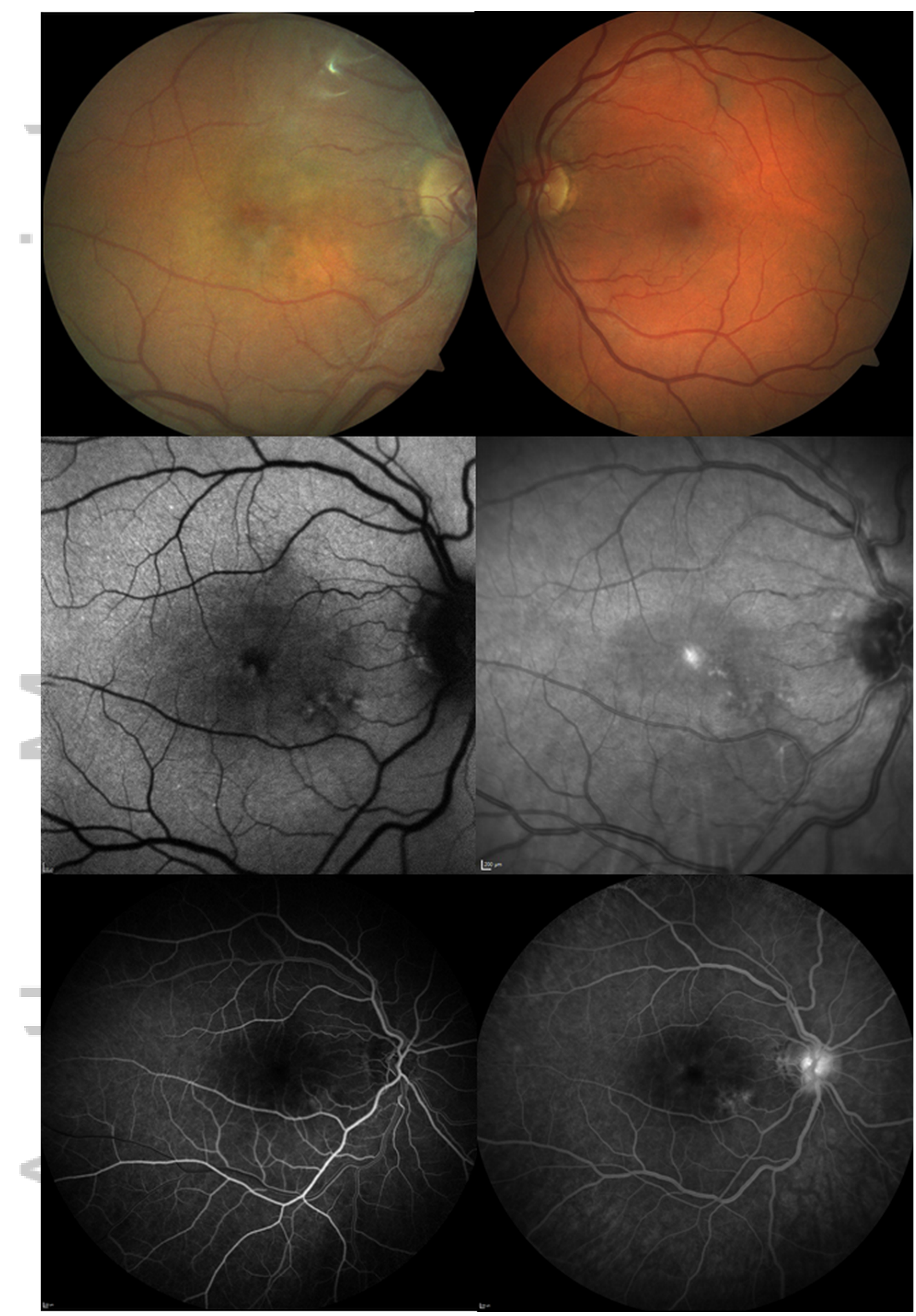

CE0_12944_F1.png

This article is protected by copyright. All rights reserved. 


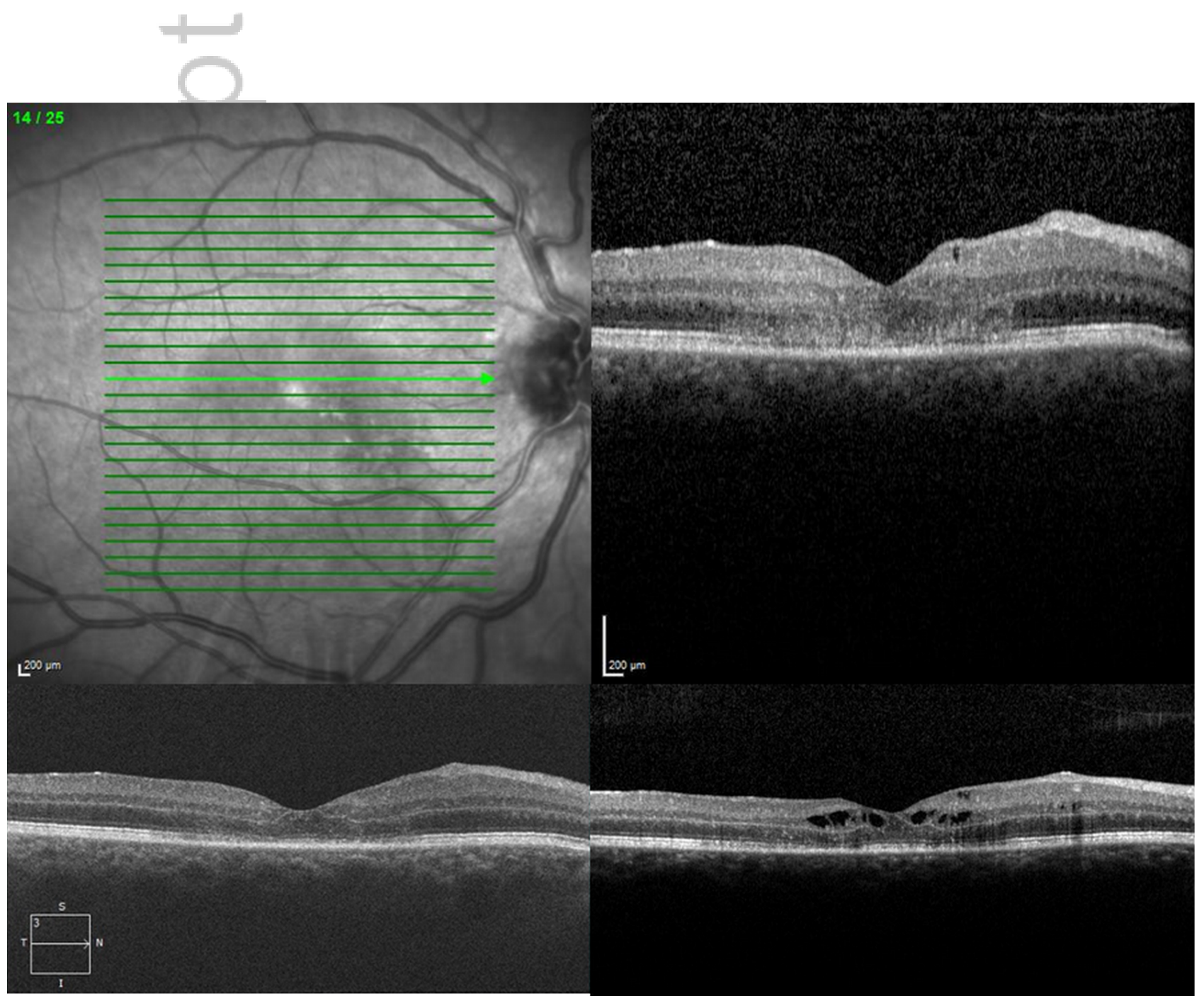

CEO_12944_F2.png

This article is protected by copyright. All rights reserved. 


\section{University Library}

\section{- M M I N E R VA A gateway to Melbourne's research publications}

Minerva Access is the Institutional Repository of The University of Melbourne

Author/s:

Ong, D;Harper, CA;Fagan, $\mathrm{X}$

Title:

Clinical case of influenza A with outer retinal maculopathy

Date:

2017-09-01

Citation:

Ong, D., Harper, C. A. \& Fagan, X. (2017). Clinical case of influenza A with outer retinal maculopathy. CLINICAL AND EXPERIMENTAL OPHTHALMOLOGY, 45 (7), pp.745-747. https://doi.org/10.1111/ceo.12944.

Persistent Link:

http://hdl.handle.net/11343/292816 